\title{
Research on the Quality Assurance System of Financial and Economic University Graduate Students under the Background of Big Data
}

\author{
Rong $\mathrm{Yu}^{*}$ \\ School of Management Science and Engineering \\ Nanjing University of Finance and Economics \\ Nanjing, China
}

\author{
Lei Huang \\ School of Management Science and Engineering \\ Nanjing University of Finance and Economics \\ Nanjing, China
}

\begin{abstract}
Big data has become an important field for international competition and national development, and urgent demand about big data has been created. This paper discuss the gap between current situation of graduate student education and the demand under big data. Dissipative structure theory is used to analyze the openness, fluctuation and non-linearity of graduate education quality assurance system. The quality assurance system could be improved from three aspects, that is opening the system and involving stakeholders, promoting the non-Linearity of the system and developing a more orderly structure of the system.
\end{abstract}

Keywords-quality assurance system; financial and economic university; graduate student; big data

\section{INTRODUCTION}

In recent years with the rapid development of cloud computing, artificial intelligence and mobile communication , human society has been brought into a new era of "big data". Big data has become an important field for international competition and national development, and urgent demand about big data has been created. "National big data strategies" was put forward by the Fifth Plenary session of the 18th Central Committee of the Communist Party of China. "Big data" has been mentioned multiple times in the report on the work of the government. Besides, the State Council has issued the Platform for Action to promoting the development of big data. The popularization of computing devices and the gradual maturity of cloud computing technology have led to a degree that has started to trigger changes. As far as the education industry is concerned, the wide use of various education management systems has led to the substantial increase of a large amount of learning information and student information. Education industry is facing inevitable problem of big data.

With the advent of big data era, the traditional education industry has received strong impact. The learning methods and learning requirements of learners have also undergone great

Sponsored by the following programs: major project of degree and graduate education of Nanjing University of Finance and Economics named "Research on graduate training program and quality evaluation based on big data" and teaching reform project of Nanjing University of Finance and Economics "Discussion on the reform of personnel training program of management science based on big data" (No. JGY1858). changes. The former face-to- face courses in universities have been difficult to meet the learning needs of innovative talents. Personalized and fragmented learning has gradually become the mainstream, which is also the reason for the rise of online education wave. Education is undergoing a historic transformation of digitization, networking and globalization. A large number of "breadcrumbs" learning data will help course teachers make correct teaching decisions, adjust teaching plans, predict teaching achievements and form systematic teaching management. Therefore, how to reform the personnel training program for finance and economics university in the context of big data has become an urgent problem to be solved.

\section{GAP BETWEEN CURRENT GRADUATE EDUCATION AND CURRENT TALENT DEMAND}

Graduate education is the diploma education of training high-level specialized talents after undergraduate education, which is the highest stage of higher education. The training goal is to train elite talents in various fields or industries in society. With the rapid development of the enrollment scale and the change of talent demand, the training objective has changed from a single research-based elite training to a diversified research, application and inter-disciplinary talent training.

At present, the education type structure and talent training mode of Chinese graduate students are undergoing a great transformation. At the same time, the industry is in a crucial period of transformation and upgrading. The requirements of the industry on high technology labor force have been changed. The development of high technology industry needs excellent talents as a support. Because the graduate education and industry demands for talent effectively to promote industrial upgrading and development play a role as a great support. Therefore, the exploring to establish new type of cohesion between graduate education and demand mechanism, realize the benign interaction and promote the upgrading of industry development in our country has important practical significance.

Lots of foreign universities set their majors about data management in business schools, which is in line with the principle of ownership problem-oriented and methodologically 
oriented. Foreign countries mainly offer majors and courses related to data science in graduate stage. But with the improvement of students' data processing ability, some universities start relevant majors during undergraduate stage, such as business analytics, business intelligence, business data analytics and science in business analytics. The education path of the above majors are mainly as follows: According to the data characters and problem oriented, corresponding data model (normalized model, data model and simulation model) are created under the background of big data. Computer tools and software (data analysis tools and optimization analysis tools) are used to formalize problems. The results should be analyzed combining corresponding background.

According to the graduate training process in domestic financial and economic universities, there are many problems in the current graduate education in the context of big data: the course goal is unitary, basic theory, research methods, interdisciplinary knowledge and other aspects, as well as innovation ability training, scientific spirit and academic quality are ignored [1]; The course contents are simple, even repeats many undergraduate courses. The proportion of frontier knowledge is low [2]; Teaching methods of the course are traditional and lack attention on the academic inquiry and knowledge construction process [3]. On the one hand, the understanding on nature and importance of graduate course teaching is in a state of lacking. For a long time, many countries in the world have considered that there is no substantial difference between graduate course and undergraduate course, and they fail to truly form a joint of research-teaching-learning [4]. On the other hand, the graduate courses emphasizes high theoretical and practical value, students have different starting point in teaching practice. The curriculum setting reflects the "arbitrariness" and lacks quality standards. The important content for graduates in financial and economic universities in China is how to establish the quality assurance system for graduates, provide individualized and multi-dimensional course learning support for students with diverse starting points, effectively improve the teaching quality of courses, and give full play to the educational function of graduate courses.

\section{DISSIPATIVE STRUCTURE ANALYSIS OF EDUCATION QUALITY ASSURANCE SYSTEM OF GRADUATE STUDENTS IN FINANCIAL AND ECONOMIC UNIVERSITIES}

Education quality assurance system of graduate students needs to constantly exchange material, energy and information with internal and external stakeholders such as the government, universities, students and employers. Therefore, it is reasonable to analyze its dissipation structure [5]. The analysis of the dissipative structure characteristics of the self-organizing graduate education quality assurance system can not only further enrich the theoretical results of the research in this field, but also provide inspiration for the further establishment and improvement of education quality assurance system for Chinese financial and economic universities. The following figure shows the evolution development process of the system.

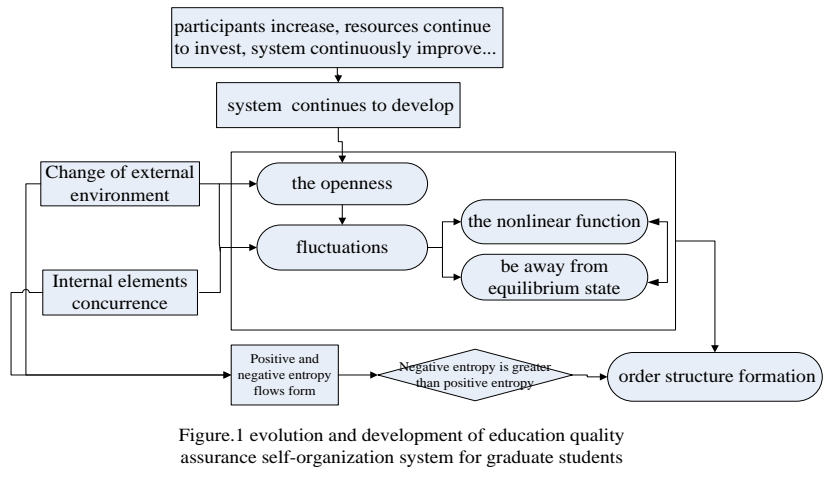

\section{A. Openness of Graduate Education Quality Assurance System}

Graduate education quality assurance system is a highly open system, which embody in two aspects: opening to the outside and inside. The graduate education quality assurance system constantly gets various resources from government, business, academia, students, their families and other stakeholders, and brings the resource, energy and information into the system; At the same time, due to the openness of the internal system, the internal departments and various activities of graduate education quality assurance system exchange information, correlate and restrict each other. The power of system operation and evolution structure are dependent on internal talents, capital, equipment, information, knowledge, system and other elements' connection and flow [6].

\section{B. Fluctuations of Education Quality Assurance System of Graduate Students}

The fluctuation of graduate education quality assurance system is reflected on demand and environmental changing two aspects. For the development of graduate education quality assurance system, stakeholders will be required to constantly input complementary heterogeneous resources, or new partners will be added to provide impetus. If the resources provided by existing stakeholders cannot meet the development needs, one or more subjects will be separated from the system. The elements and boundaries of the system will change. At the same time, the external society of the postgraduate education quality assurance system is constantly changing. Big data environment has changed the traditional appearance of education. The application basis of big data is the possession of massive data, which involves the challenges of data storage technology and technical challenges for data processing and analysis. Secondly, data collection and problem solving analysis are the core links, which will change the process of quantitative research for financial and economic universities. (as shown in Fig. 2.) 


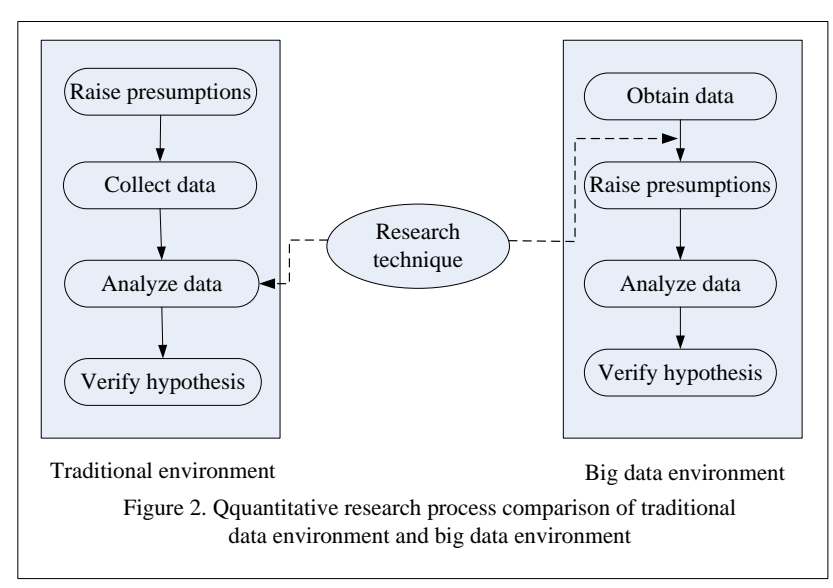

\section{Nonlinear Effect of Education Quality Assurance System of Graduate Students}

The relationships between subsystems and elements within the quality assurance system of education of graduate students are complex and non-linear, rather than simple causality or linear dependence. From the point of stakeholders, the training units of the graduate education quality assurance system (such as universities and scientific research institutes, etc.), students (graduate of postgraduate students and alumni, etc.) are connected to the cooperation unit (unit of choosing and employing persons, intermediary organizations and joint training institutions, etc.) under the guidance of the government (relevant administrative department).Due to the large number of stakeholders, complex hierarchical structure and diverse target functions, resources such as human and property input into graduate education quality assurance system are not simply linear and positive correlation with the output of talent cultivation, knowledge products and social services, but nonlinear effect of multiple variables [7].

\section{Disequilibrium State of Graduate Education Quality Assurance System}

Graduate education quality assurance system is a system that is far from equilibrium, which embodies in static composition and dynamic evolutionary two aspects. The input resources, expected returns and the ability of organization of all subjects have a great difference because of the graduate education quality assurance system involving government, cultivating units, cooperation unit, students and many other stakeholders. And the internal subjects in the system and knowledge flow, information flow, capital flow exchanged with the outside world are changing all the time. Besides, graduate education quality assurance system should get more results in improving the quality of education, the satisfaction of all stakeholders and so on for survival and development that also means that the graduate education quality assurance system should not meet and run into a state of equilibrium, but must break the balance to seek further development.

\section{CONCLUSION AND INSPIRATION}

Based on the background of big data and dissipative structure theory, the existing problems and the dissipative structure of graduate student education in financial and economic universities are discussed in this paper. With the rapid development of Internet data technology, the demanding on the quality of graduate education from all walks of life is increasingly higher and higher. As a result, education managers need to use the successful experience of foreign universities education quality assurance system for reference reasonably on the basis of present situation of our country. The following three aspects could be referred.

\section{A. Opening the System and Involving Stakeholders}

It can be seen from the literature on the graduate student quality assurance system of foreign financial and economic universities, stakeholders such as the government, cooperative units and the public are largely involved in the quality assurance system. The main basis for the quality assurance activities of Chinese graduate education is still the graduate education evaluation system established in 1985. The activities are dominated by the evaluation led by the state administrative forces, and the degree of social participation and role needs to be further improved. Firstly, the public and other stakeholders' awareness can be improved and their enthusiasm and initiative can be enhanced by publicizing education and other ways. Secondly, the government and university administrators should learn from the experience of universities in developed countries in improving the governance structure and feedback and communication mechanism in order to constantly broaden the channels for stakeholders to participate in.

\section{B. Promoting the Non-Linearity of the Quality Assurance System}

Most financial and economic universities in China have carried out the quality assurance activities of graduate education, but only the staff of the graduate school and some managers are involved. The internal quality assurance system has not been established, and the corresponding functional structure needs to be further improved. Most foreign financial and economic universities maintain the stability and development of the whole quality assurance system through multiple governance structure, dynamic funds adjustment and communication of feedback mechanism. Financial and economics universities need to build flexible network organization and internal management mechanism to integrate and optimize internal resources of system. To maintain moderate openness on the basis of self-structural integrity and independence, universities can obtain material, energy and information which are needed for development continuously through the interaction with the external environment. And then they can ensure the graduate education quality assurance system to be self-organized.

\section{Developing a More Orderly Structure of the System}

Foreign university administrators constantly adjust and promote the balance of the system according to the changes of economic society, and reform the governance structure, fund composition, information communication and other aspects. 
The fund sources of domestic financial and economic universities mostly depend on government appropriation. It lacks the impetus for reform because the assessment result such as subject evaluation has little impact on the governance structure and funds. Therefore, government administrators should make dynamically adjusted input budget linked to assessment results according to the different types, objectives and emphases of graduate education in different universities. Assessment indicators on the evaluation and assurance activities of graduate education quality should be set in order to achieve the target of "different levels and types of universities have scientific orientation and execute their duties and highlight the school characteristics".

\section{ACKNOWLEDGMENT}

This paper is sponsored by the following programs: major project of degree and graduate education of Nanjing University of Finance and Economics named "Research on graduate training program and quality evaluation based on big data " and teaching reform project of Nanjing University of Finance and Economics "Discussion on the reform of personnel training program of management science based on big data" (No. JGY1858).

\section{REFERENCES}

[1] Wang Xia, Bian Qing, Sun Junhua. On the graduate students curriculum system construction of academic degree [J]. Degree and postgraduate education, 2015(10) : 30-34.(In Chinese).

[2] Yang Chunmei, Tao Hong. On the integration of postgraduate curriculum study and scientific research training $[\mathrm{J}]$. Degree and postgraduate education, 2008(3) : 9-12. (In Chinese).

[3] Zhang Liping, Zhao Zhangyao, Xu minna, etc. Reconstruction and optimization of postgraduate curriculum system -- thinking and practice of postgraduate curriculum construction in Zhejiang university [J]. Degree and postgraduate education, 2013(6) : 38-41. (In Chinese).

[4] Clark. The place of inquiry - scientific research and postgraduate studies in modern universities.[M] Wang Chengzhu, translation. Hangzhou: Zhejiang education press, 2001: 220.(In Chinese).

[5] Liu Yuan, Zhang Jiangong. Research on postgraduate education quality assurance system from the perspective of dissipative structure theory -taking the university of Warwick as an example [J]. Research on postgraduate education, 2017 (2) : 89-95. (In Chinese).

[6] Zhang Mingguo. The technology-culture and the theory of dissipative structure - A self-organizational perspective of studying technology and culture [J].Journal of system science, 2011(2):11-16.(In Chinese).

[7] Niko Kova .Self-Organization in Non-Equilibrium system [M].Beijing: Science Press, 1986. 